\title{
Meningkatkan kemahiran penambahan dan penolakan pecahan pelajar tahun 4 melalui Fraction Cipher
}

\author{
Improve adding and subtracting skills $4^{\text {th }}$ year students through Fraction Cipher \\ Mohd Afifi Bahurudin Setambah \\ Institut Pendidikan Guru Kampus Bahasa Melayu, Lembah Pantai, \\ Kuala Lumpur, Malaysia \\ *email: mohdafifi@ipgkbm.edu.my
}

DOI: $\underline{\text { https://doi.org/10.37134/jpsmm.vol9.1.4.2019 }}$

\begin{abstract}
Abstrak
Kajian ini bertujuan untuk menentukan dan mengatasi masalah yang dihadapi oleh pelajar di dalam topik operasi penambahan dan penolakan pecahan. Tinjauan awal dilakukan melalui semakan latihan dan ujian pra mendapati pelajar mempunyai masalah terhadap topik berkenaan. Hasil tinjauan tersebut seramai 10 orang pelajar telah dijadikan sampel kajian. Ia melibatkan pelajar tahun 4 di salah sebuah sekolah sekitar Wilayah Persekutuan Kuala Lumpur. Pembinaan Fraction Cipher dilakukan sebagai bahan bantu mengajar bagi mengatasi masalah tersebut. Tiga instrumen utama digunakan dalam kajian ini seperti ujian pencapaian matematik (pecahan), instrumen pemerhatian dan instrumen temu bual separa struktur. Kajian dimulakan dengan ujian pra, intervensi selama empat minggu, ujian pos dan temubual pelajar seminggu selepas ujian pos dijalankan. Hasil kajian ini diharapkan dapat memberikan gambaran jelas kemampuan Fraction Cipher sebagai bahan bantu pengajaran alternatif yang dapat dilaksanakan oleh guru dan pendidik dalam mengamalkan pengajaran dan pembelajaran untuk abad ke-21. Kajian ini juga diharapkan dapat membantu Aspirasi dan Misi Negara Malaysia dalam membangunkan modal insan yang berjaya.
\end{abstract}

Kata Kunci: Pecahan, Pembelajaran Berasaskan adventure, Gamifikasi, Fraction Cipher, Pengajaran Matematik

\begin{abstract}
This study aims to determine and address the problems faced by students in the topics of operations of addition and subtraction. Initial reviews were conducted through document reviews and pre-tests find out students had problems with the topic. As a result of this survey a total of 10 students will be sampled. It involves Standard 4th year students at one of the schools around Kuala Lumpur. Fraction Cipher is used as a teaching aid to solve the problem. The three main instruments used in this study are mathematical achievement test (fraction), observation instrument and semi-structured interview instrument. The study began with pre-test, four-week intervention, post-test and student interviews a week after the post-test. The results of this study are expected to provide a clear picture of Fraction Cipher's capabilities as an alternative teaching tool that can be used by teachers and educators in practicing teaching and learning for the 21 st century. The study is also expected to assist Aspirasi and the National Mission of Malaysia in developing successful human capital.
\end{abstract}

Keywords: Fraction, Adventure Based Learning, Gamification, Fraction Cipher, Teaching Mathematics 


\section{PENGENALAN}

Matematik merupakan instrumen yang sesuai digunakan untuk mengembangkan profisiensi intelektual individu. Antara aspek yang perlu dikembangkan ialah penaakulan logik, visualisasi ruang, analisis dan pemikiran abstrak pelajar. Perkara ini dapat dilakukan apabila mereka mempelajari kemahiran numerasi, menaakul, berfikir dan menyelesaikan masalah melalui pembelajaran matematik (Kementerian Pendidikan Malaysia, 2014). Terdapat pelbagai topik matematik yang dipelajari oleh pelajar dari tahun 1 hingga tahun 6. Topik-topik ini menjadi asas kepada perkembangan matematik mereka pada masa hadapan. Antara topik yang dipelajari oleh mereka ialah nombor dan operasi, sukatan dan geometri, perkaitan dan algebra,statistik dan algebra (Kementerian Pendidikan Malaysia, 2014). Di dalam topik-topik tersebut, terdapat subtopik yang lebih kecil. Sebagai contoh topik nombor dan operasi mengandungi subtopik yang lebih kecil seperti nombor bulat, pecahan, perpuluhan, peratus dan wang. Oleh itu, kajian ini hanya memberi fokus kepada subtopik pecahan sahaja.

Pecahan telah dilihat sebagai suatu nombor yang memiliki sifat yang unik berbanding dengan nombor bulat yang pernah dipelajari oleh pelajar sebelum itu. Keunikan sifatnya telah menyebabkan ia nya sukar difahami. Topik ini sering berlaku miskonsep seperti mana yang dijelaskan oleh Zakiah Salleh, Norhapidah Mohd Saad, Mohamad Nizam Arshad, Hazaka Yunus, dan Effandi Zakaria (2013). Menurut mereka, terdapat empat perkara yang sering dilakukan oleh pelajar semasa menjawab soalan operasi penambahan dan penolakan pecahan iaitu kesilapan sistematik, kesilapan rawak, kesilapan kecuaian dan tidak tahu menjawab soalan pecahan. Apabila diselidiki punca utama kesilapan mereka adalah kurang kefahaman terhadap proses yang terlibat, kesukaran dalam menurunkan pecahan, kesukaran menukarkan pecahan kepada penyebut yang sama, kesilapan dalam pengiraan, kesukaran menukar pecahan tidak wajar kepada nombor bercampur dan menggunakan proses yang salah.

Hal ini juga terjadi kepada penyelidik di mana pelajar didapati melakukan perkara yang sama semasa melaksanakan operasi penambahan dan penolakan pecahan. Kesilapan pelajar di dalam proses penambahan pecahan ditunjukkan melalui Rajah 1 . Hal ini terjadi apabila berlaku miskonsep dari satu konsep kepada konsep yang lain. Pelajar didapati masih membawa konsep operasi penambahan nombor bulat kepada topik penambahan nombor pecahan. Ini dapat dilihat menerusi jawapan soalan 1, 2, 3, 4, 6, 7 dan 8 yang pelajar berikan. Mereka didapati menambahkan pengangka dan pengangka, serta penyebut dan penyebut. Ini jelas menunjukkan bahawa miskonsep telah berlaku kepada mereka. Perkara ini perlu diatasi segera kerana penguasaan pecahan akan mempengaruhi pengetahuan algebra dan pencapaian matematik kelak (Lortie-Forgues \& Siegler, 2017). Hal yang sama juga berlaku apabila penyelidik menyemak latihan operasi penolakan pelajar.

Perkara ini perlu dan dapat diatasi melalui proses pengajaran dan pembelajaran. Salah satu aspek yang boleh meningkatkan kefahaman pelajar adalah melalui penggunaan bahan bantu mengajar yang efektif (Mohd Amin, Mohd Faeez, Kalthom, \& , Muhammad Syakir, 2016). Justeru, inovasi dan transformasi perlu dilakukan menerusi pembangunan dan pembinaan bahan bantu mengajar. Penggunaan bahan bantu mengajar amat penting agar guru dapat menerangkan sesuatu perkara dengan lebih tepat dan jelas berbanding dengan penerangan secara lisan sahaja. Hal ini dapat memastikan penyampaian pengajaran dan pembelajaran dapat dilaksanakan dengan lebih efektif (Mohd Amin et al., 2016). 
Rajah 1. Kesilapan operasi penambahan pelajar tahun 4

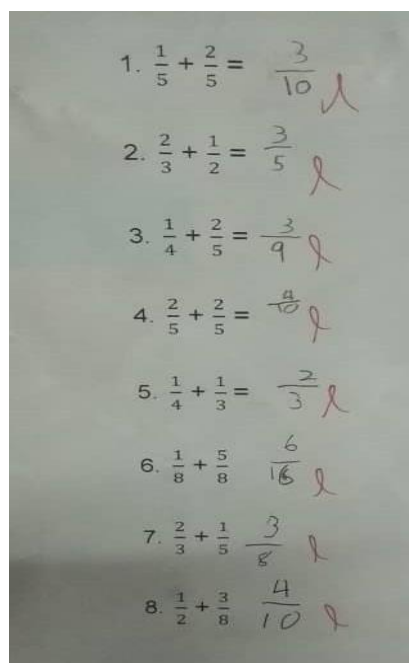

Keperluan membangunkan bahan bantu mengajar ini amatlah signifikan. Perkara ini sekaligus mampu menukar kaedah pengajaran dan pembelajaran guru tersebut ke arah yang lebih baik. Terdapat beberapa kaedah pengajaran guru yang sering dipraktikkan oleh guru matematik agar memupuk amalan pengajaran dan pembelajaran yang berkesan. Antaranya ialah kaedah kuliah (pengajaran lisan dan persembahan bahan), perbincangan, kaedah inkuiri, kaedah penemuan, pembelajaran koperatif, kaedah projek (Mok, 1993; Noraini, 2005; Mohd Afifi, 2017). Walau bagaimanapun, guru masih mengekalkan amalan pengajaran dengan kaedah semakan jawapan latihan, kuliah dan latihan individu semasa mengendalikan kelas matematik. Ini kerana mereka lebih menumpukan kepada peningkatan pencapaian akademik (Azhari \& Zaleha, 2013; Koh et al., 2008). Guru juga dikatakan masih mengamalkan kaedah berpusatkan guru iaitu sebagai penyampai maklumat dan penunjuk cara, manakala pelajar sebagai pemerhati dan penerima pengetahuan (Tengku Zawawi, Ramlee,\& Abdul Razak, 2009; Mohd Afifi, Nor'ai, \& Mazlini, 2017).

Bagi pengajaran dan pembelajaran matematik, terdapat tujuh amalan pengajaran guru matematik yang sering digunakan. Dua daripada tujuh amalan dipraktikkan oleh kebanyakan guru iaitu penekanan kepada pemahaman konsep dan penggunaan model Polya dalam pengajaran dan pembelajaran. Selain itu, guru juga sering menggunakan contoh yang sesuai semasa penjelasan sesuatu topik matematik. Penggunaan istilah matematik yang mudah difahami dan juga bahan maujud telah menjadi kebiasaan oleh guru-guru matematik. Terdapat juga guru yang menggunakan peta minda seperti i-Think dan model Heuristik semasa sesi pengajaran dan pembelajaran mereka. Ada juga dalam kalangan mereka mengambil kira faktor kebolehan murid semasa merancang sesi pengajaran dan pembelajaran mereka (Nor'ain, Marzita, Mazlini, Abdullah, \& Amalina, 2015). Menurut Noraini (2005), terdapat beberapa faktor yang menghalang pembelajaran matematik iaitu set fikiran (mind set), latih tubi kurang berkesan, penghafalan sebelum kefahaman, kurang penglibatan pelajar secara aktif, kemusykilan pelajar tidak didiagnostik dan latihan yang tidak mencabar. Perkara ini telah menjadi amalan para guru matematik dan telah dikenal pasti oleh beliau semasa menjalankan kajian.

Apabila penyelidik membuat refleksi kembali, penyelidik juga mendapati bahawa kaedah yang penyelidik laksanakan semasa sesi pengajaran dan pembelajaran tidak memberikan impak yang positif kepada mereka. Penyelidik hanya menggunakan contoh dan menulis langkah pengoperasian penambahan dan penolakan pecahan tanpa bantuan bahan bantu mengajar. Hal ini dapat dilihat kesannya apabila sering kali penyelidik mendapati pelajar selalu mengeluh tidak faham, bertanyakan kembali proses penambahan dan penolakan pecahan. Hal ini dapat direkodkan menerusi luahan kata mereka seperti "tak faham la cikgu","pastu macam mana cikgu","aduh,tak boleh mcm tu ye cikgu". Ini membuktikan bahawa mereka sering bergantung kepada jawapan guru dan tidak memahami lagi konsep yang telah diajar oleh guru mereka. 
Kesimpulannya, penyelidik ingin menegaskan bahawa amalan pengajaran yang dikemukakan adalah berdasarkan beberapa tinjauan kajian yang telah dijalankan oleh penyelidik khususnya amalan pengajaran dan pembelajaran matematik dan amalan yang serin penyelidik jalankan. Justeru, guru diharap melakukan transformasi dan reformasi agar mempraktikkan amalan pengajaran dan pembelajaran yang memupuk kemahiran serta meningkatkan nilai tambah modal insan. Perkara ini boleh dimulakan dengan membina bahan pengajaran dan pembelajaran yang tepat. Bahan yang berinovasi mampu memberikan kesan yang lebih baik. Kesan bahan yang dibina perlulah diuji keberkesanannya. Oleh itu, kajian ini bertujuan untuk mengenal pasti kebolehgunaan Fraction Cipher bagi meningkatkan pencapaian matematik bagi topik pecahan.

\section{Fraction Cipher}

Fraction Chipher (FC) (Rajah 3) merupakan satu pembaharuan dalam arena pendidikan negara yang melibatkan unsur pembelajaran bahasa Melayu dan Matematik. Unsur penyerapan ini merupakan galakan yang dicadangkan oleh pihak Kementerian Pendidikan Malaysia. FC merupakan gabungan perkataan pecahan (Fraction) dan cipher. Fraction (pecahan) merupakan topik yang dipilih untuk dibuat penambahbaikan. Manakala Cipher merupakan satu kod kunci yang digunakan oleh oleh seseorang untuk tujuan menyampaikan maklumat secara rahsia (Yeoh, Mohd Afifi, Ket, \& Narmal, 2015). Gabungan dua perkataan ini membentuk FC. Gabung jalin ini dilaksanakan agar konsep numerikal yang tidak asing bagi matematik dengan Bahasa Melayu. Hal ini dapat meningkatkan kosa kata pelajar berkaitan Bahasa Melayu walaupun FC dibangunkan khas untuk pecahan dalam matematik. Hal ini amat baik dijalankan kerana dapat menyatupadukan dua subjek dalam satu bahan. Dengan kata lain, FC adalah bahan bantu pengajaran yang mengambil kira elemen merentas kurikulum seperti mana yang disarankan (Kementerian Pendidikan Malaysia, 2014).

\section{Rajah 2. Gambar Fraction Cipher}

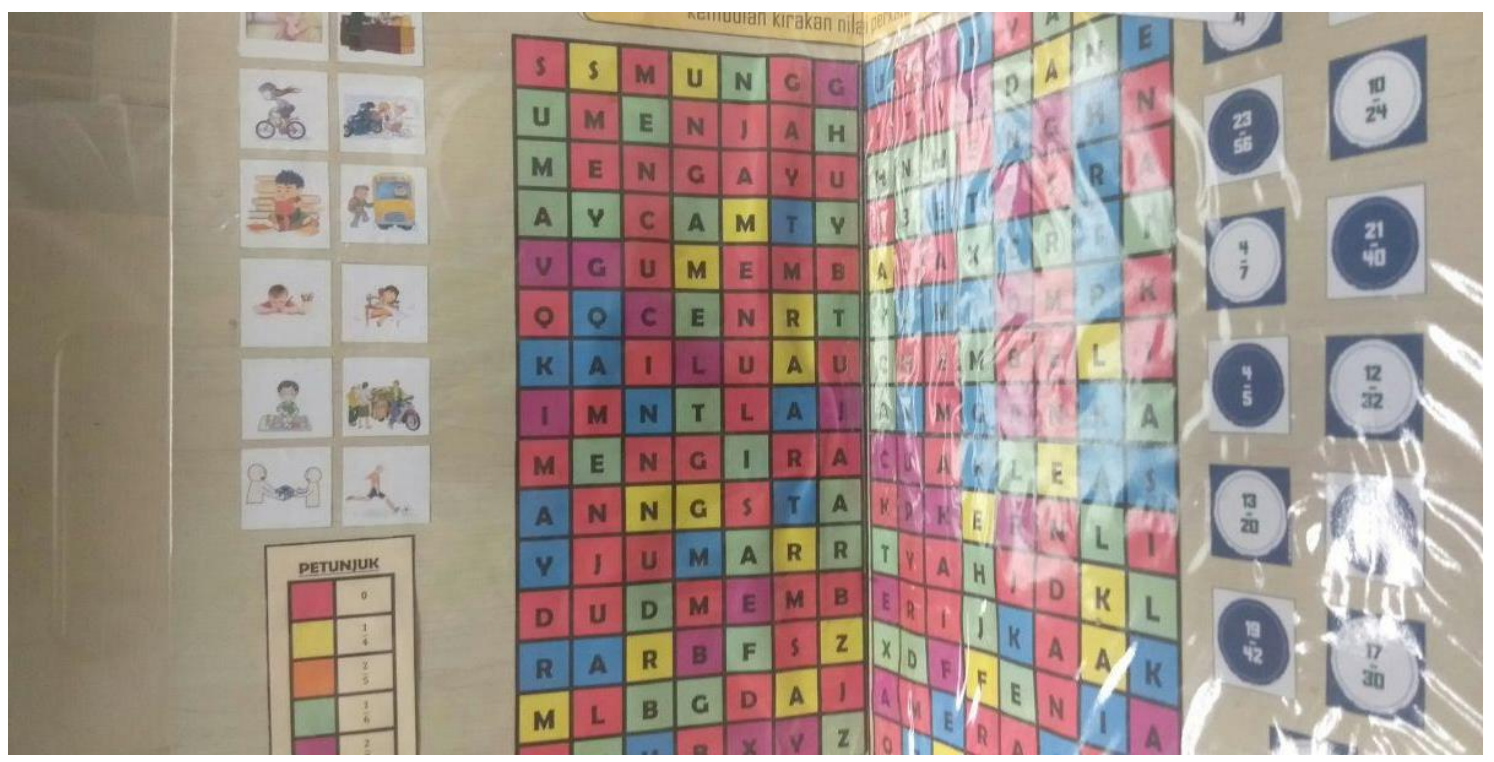

FC perlu dipraktikkan menggunakan satu kaedah pembelajaran yang menyeronokkan agar dapat meningkatkan lagi keberkesanannya melalui penerapan konsep gamifikasi. Gamifikasi yang dimaksudkan ini menggabungkan cara pengajaran dan pembelajaran operasi pecahan dalam Matematik dan pengukuhan kosa kata Bahasa Melayu melalui permainan teka silang kata versi kod kriptografi. Menurut Huang dan Soman (2013), gamifikasi merupakan kraf yang menghasilkan unsurunsur yang menyeronokkan dan ketagihan yang terdapat dalam permainan dan menggunakannya untuk aktiviti kehidupan seharian. Hal ini akan membantu guru menarik minat dan perhatian pelajar ke arah sesi pengajaran dan pembelajaran yang disampaikan. Gamifikasi merujuk kepada aplikasi unsur reka bentuk permainan untuk aktiviti bukan permainan dan telah digunakan untuk pelbagai konteks termasuk pendidikan (Nah, Zeng, Telaprolu, Ayyappa, and Eschenbrenner, 2014). FC 
memegang konsep pembelajaran matematik perlu melibatkan aktiviti yang menyeronokkan, minat terhadap perkara yang dikecapi, pelajar terlibat secara aktif, dan melibatkan kehidupan seharian. Empat daripada enam elemen yang disarankan oleh Mohd Afifi, Nor ain dan Mazlini (2017) telah diterap semasa pembinaan FC. Konsep gamifikasi ini dipilih kerana kesannya yang baik terhadap peningkatan pembelajaran pelajar (Pradhana \& Latifah, 2013) khususnya peningkatan kosa kata dan aspek pecahan pelajar.

Selain itu, FC juga menggunakan kaedah pembelajaran yang menyeronokkan iaitu Adventure Based Learning (ABL). Melalui tinjauan literatur yang telah dibuat, kaedah ini jarang dilaksanakan untuk tujuan pembelajaran bahasa Melayu dan matematik. Kaedah ABL ini dipilih berdasarkan impak yang telah terbukti berdasarkan kajian yang dapat menghasilkan seorang pelajar yang berdaya saing, mampu memimpin, meningkatkan kemahiran komunikasi, dan membantu mengukuhkan kemahiran berfikir kritis pelajar. Kaedah ini juga bertepatan kaedah pembelajaran abad ke-21(Mohd Afifi, Nor'ain, \& Mazlini, 2016).

Inovasi ini juga menekankan konsep "Sake Beda". Perkataan Sake merujuk kepada "sama = kekal" manakala perkataan Beda merujuk kepada "beza x darab". Teknik ini merupakan elemen sangat penting dalam menyelesaikan masalah operasi asas pecahan dalam kalangan pelajar sekolah rendah. Di samping itu, murid sekolah juga akan dapat menambah kosa kata Bahasa Melayu melalui permainan ini secara tidak langsung. Sebagai contoh, antara perkataan yang dibekalkan seperti kata kerja transitif iaitu membeli, memberi dan lain-lain lagi. Perkataan yang dibekalkan ini merujuk kepada tema setiap set permainan. Ini sekali gus mampu meningkatkan peengetahuan pelajar berkenaan dalam bidang bahasa Melayu.

Berikut adalah perbezaan antara pembelajaran pecahan menggunakan FC dan pembelajaran pecahan secara konvensional:

Jadual 1 FC Versus Pengajaran Konvensional

\begin{tabular}{|c|c|c|}
\hline Method & Fraction Chipher (FC) & Konvensional \\
\hline $\begin{array}{l}\text { Kandungan } \\
\text { Pengajaran }\end{array}$ & $\begin{array}{l}\text { Pengajaran dan pembelajaran } \\
\text { menggunakan bahasa Melyu dan } \\
\text { menerapkan elemen bahasa Melayu } \\
\text { (aspek kosa kata) }\end{array}$ & $\begin{array}{lcr}\text { Pengajaran } & \text { dan } & \text { pembelajaran } \\
\text { menggunakan } & \text { bahasa } & \text { Melayu } \\
\text { sahaja } & & \end{array}$ \\
\hline $\begin{array}{l}\text { Kandungan } \\
\text { Pengajaran }\end{array}$ & $\begin{array}{l}\text { Operasi penambahan dan operasi } \\
\text { penolakan bagi pecahan wajar }\end{array}$ & $\begin{array}{l}\text { Operasi penambahan dan operasi } \\
\text { penolakan bagi pecahan wajar }\end{array}$ \\
\hline $\begin{array}{l}\text { Bahan Bantu } \\
\text { Mengajar }\end{array}$ & $\begin{array}{l}\text { Pembelajaran secara berkumpulan } \\
\text { menggunakan FC sebagai bahan } \\
\text { pengajaran dan pembelajaran }\end{array}$ & $\begin{array}{l}\text { Pembelajaran secara berkumpulan } \\
\text { tanpa menggunakan FC (pen dan } \\
\text { kertas) }\end{array}$ \\
\hline Kaedah & Menggunakan pendekatan & kuliah, latih tubi, berpusatkan guru \\
\hline $\begin{array}{l}\text { Pengajaran dan } \\
\text { Pembelajaran }\end{array}$ & $\begin{array}{l}\text { berasaskan adventure (Mohd Afifi, } \\
\text { Nor'ain, Mazlini, 2017) }\end{array}$ & \\
\hline Tugasan & $\begin{array}{l}\text { Tugasan latihan di dalam buku } \\
\text { latihan }\end{array}$ & $\begin{array}{l}\text { Tugasan latihan di dalam buku } \\
\text { latihan }\end{array}$ \\
\hline
\end{tabular}

Kesimpulannya, FC adalah satu projek pembangunan bahan bantu mengajar yang menekankan beberapa elemen penting. Pertama, gabungan melibatkan matematik dan bahasa Melayu, Kedua, menerapkan konsep gamifikasi agar dapat meningkatkan minat pelajar. Ketiga, menggunakan kaedah ABL semasa pengajaran dan pembelajaran. Terakhir, menekankan konsep "Sake Beda" semasa melaksanakan operasi penambahan dan penolakan pecahan. Justeru, diharap FC mampu memberikan implikasi kepada pelajar agar dapat meningkatkan operasi penambahan dan penolakan bagi topik pecahan. FC dijangka mampu memberi impak ke atas aspek modal insan pelajar khususnya kemahiran berfikir dan kemahiran kepimpinan. Walau bagaimanapun, kajian ini memberikan fokus kepada pencapaian matematik bagi topik pecahan sahaja. 


\section{METODOLOGI KAJIAN}

Kajian ini merupakan kajian tindakan. Kajian tindakan merujuk kepada penyelidikan terhadap amalan individu atau kumpulan bagi menambah baik amalan sedia ada. Reka bentuk kajian ini bertepatan dengan tujuan kajian di mana penyelidik ingin menyelesaikan isu dan masalah yang dihadapi di dalam proses pengajaran dan pembelajaran. Ini bertepatan dengan pernyataan Osman (2015). Menurut beliau, kajian tindakan merupakan sebahagian daripada tugasan harian yang bertujuan untuk mengatasi masalah dan meningkatkan amalan. Justeru, reka bentuk kajian ini dalah bertepatan dengan tujuan kajian.

Kajian ini menggunakan teknik persampelan bertujuan. Sampel yang dipilih merupakan pelajar tahun 4 sekolah rendah di dalam Wilayah Persekutuan Kuala Lumpur. Subjek kajian seramai 10 orang dipilih berdasarkan pemerhatian dan ujian pra yang telah dilaksanakan. Pelajar diberikan ujian pra dan ujian pos yang melibatkan topik pecahan. Ujian pra diberikan sebelum intervensi dijalankan, manakala ujian pos diberikan selepas intervensi dilaksanakan. Instrumen yang digunakan ialah ujian pencapaian matematik bagi topik pecahan, senarai semak pemerhatian dan temu bual separa struktur. Ujian pencapaian matematik mempunyai 10 soalan yang mengukur operasi penambahan dan penolakan. Senarai semak pula merangkumi pemerhatian tingkah laku pelajar sebelum dan semasa intervensi dilakukan. Manakala temu bual digunakan bagi mengukuhkan lagi dapatan data kajian. Tujuan temu bual dilakukan agar penyelidik dapat mengumpulkan data yang pelbagai selain daripada ujian pra dan ujian pos serta senarai semak.

Bagi pelaksanaan implimentasi FC pula, penyelidik telah menjalankan FC berdasarkan konsep pembelajaran berasaskan adventure. Pelajar dibahagikan kepada empat kumpulan. Penyelidik terlibat akan menjaga pusat hentian (check point). Setiap kumpulan akan diberikan FC. Mereka berbincang dengan mencari perkataan berhubung tema yang diberikan. Tema tersebut merangkumi sains, matematik, bahasa Melayu dan Sejarah. Sebagai contoh, subjek sains, tema adalah benda hidup dan benda bukan hidup. Oleh itu, terdapat beberapa perkataan yang menggambarkan benda hidup dan bukan hidup yang perlu dicari oleh pelajar di dalam papan FC. Perkataan tersebut juga mengandungi warna tertentu yang mewakili setiap pecahan. Pelajar yang telah menyelesaikan semua tugasan pecahan akan bergerak ke stesen seterusnya. Kumpulan pelajar yang dapat menyelesaikan semua tugasan dengan cepat dan tepat akan dikira sebagai pemenang. Perjalanan sesi pengajaran dan pembelajaran ini diilustrasikan melalui Rajah 3.

Pergerakan pelajar untuk aktiviti ini bermula pada check point masing-masing. Setiap check point mempunyai tema yang tertentu. Sebagai contoh kumpulan satu tema binatang ternakan. Setelah menyelesaikan tugasan tersebut, kumpulan satu akan bergerak ke check point kumpulan 2. Maka FC tema yang berbeza akan diberikan. Proses ini selesai apabila kumpulan satu tersebut telah menyelesaikan keempat-empat tugasan tema FC. Rajah 3 menunjukkan pelaksanaan aktiviti ABL dan FC yang dijalankan ke atas pelajar tahun 4 di lokasi kajian.

Rajah 3. Proses pelaksanaan intervensi FC

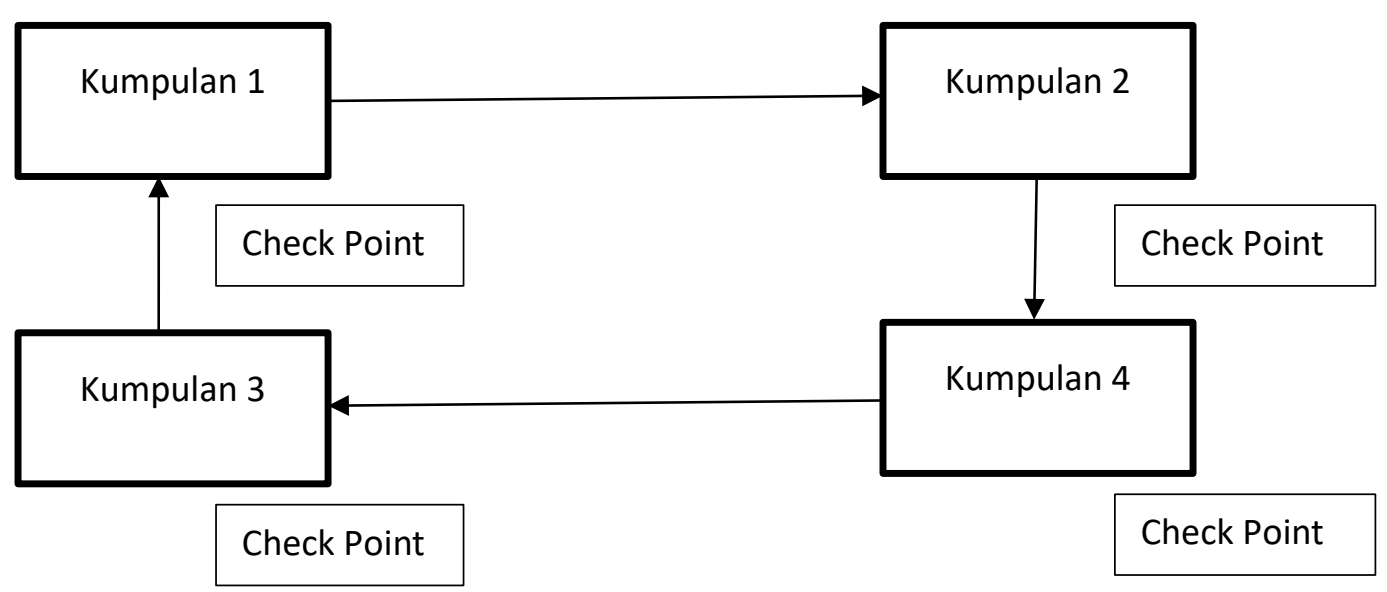


Proses kajian dijalankan dengan mentadbir ujian pra ke atas sampel. Ujian pra dijalankan secara sistematik di mana semua proses peperiksaan sebenar dipatuhi. Kedudukan sampel dipisahkan di antara satu sama lain. Semua rujukan tidak dibenarkan dibawa bersama. Pelajar hanya dibenarkan membawa pensel, pemadam dan pembaris. Setelah selesai ujian pra, pada minggu seterusnya, penyelidik terus menjalankan sesi intervensi kepada pelajar. Sesi intervensi FC dijalankan selama 3 sesi iaitu 3 pertemuan yang berbeza. Perkara yang membezakan intervensi FC adalah tema tertentu. Pada pertemuan pertama, tema sains dijalankan. Tema bahasa Melayu pada pertemuan kedua dan tema sejarah dipertemuan terakhir.

Ujian pos diberikan selepas seminggu sesi intervensi dijalankan. Ini bermakna, tempoh pelaksanaan kajian bermula pada minggu pertama iaitu ujian pra. Minggu kedua, ketiga dan keempat, pelaksanaan intervensi. Minggu kelima pula, ujian pos diberikan. Proses pentadbiran ujian pos dijalankan juga menggunakan prosedur pentadbiran yang sama dengan ujian pra. Pada minggu keenam, pelajar dipanggil untuk ditemu bual. Ini bermakna, prosedur kajian ini mengambil masa selama enam minggu. Proses pengumpulan data bagi senarai semak pula dilakukan sepanjang proses dengan bantuan ahli kumpulan penyelidik yang lain.

Semua data yang telah dikumpulkan dianalisis menggunakan pendekatan kuantitatif dan disokong oleh data kualitatif. Data kuantitatif diulas menerusi statistik deskriptif menerusi perbandingan peratusan pencapaian ujian pra dan ujian pos. Data senarai semak juga dideskriptifkan menerusi kekerapan tingkah laku pelajar sepanjang pemerhatian. Manakala data kualitatif diulas berdasarkan dapatan data temu bual ke atas pelajar. Oleh itu, berpandukan metodologi kajian ini, penyelidik berharap ia dapat mencapai tujuan kajian yang telah ditetapkan.

\section{DAPATAN KAJIAN DAN PERBINCANGAN}

Rajah 4 menunjukkan perbandingan ujian pra dan ujian pos 10 sampel kajian. Rajah 4 menunjukkan peningkatan pencapaian yang sangat baik kepada sampel 8 . Markah ujian pra sampel 8 ialah 0 markah, manakala markah ujian pos bersamaan 10 markah. Ini menunjukkan peningkatan $100 \%$ kepada sampel 8. Ini diiukuti dengan sampel 3, dari markah 1 kepada markah 10. Peningkatan bagi sampel 1 dan sampel 10 adalah sama di mana markah ujian pra mereka bersamaan 2 dan markah ujian pos mereka ialah 7. Sampel 2, sampel 4, sampel 5, sampel 6, sampel 7 dan sampel 9 juga menunjukkan peningkatan terhadap pencapaian matematik bagi topik pecahan. Hal ini boleh dilihat dengan lebih jelas menerusi Rajah 4.

Rajah 4. Dapatan kajian ujian pencapaian matematik (pecahan)

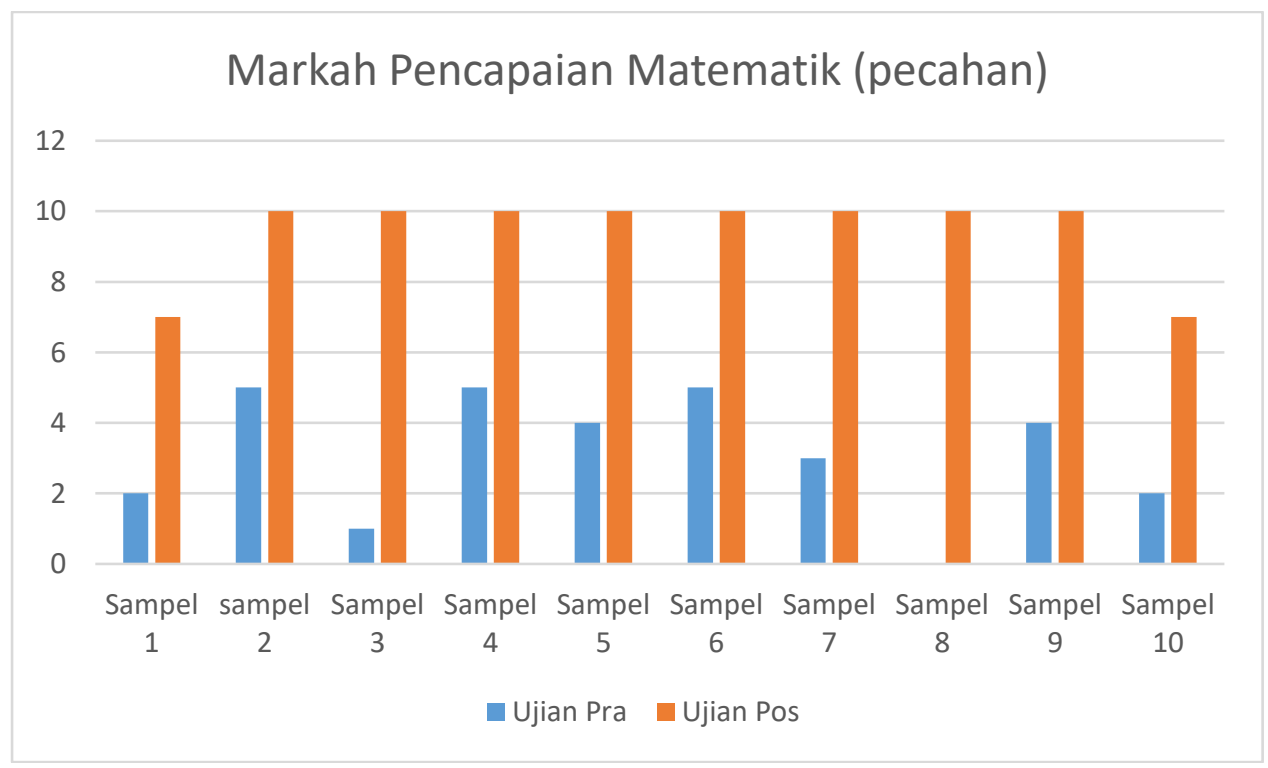


Dapatan dikukuhkan lagi dengan data kualitatif melalui temu bual separa berstruktur. 8 daripada 10 orang pelajar menyatakan bahawa mereka seronok dan berminat mempelajari topik pecahan menggunakan FC. Mereka juga ditanya tentang beberapa perkara lain seperti mana ringkasan di dalam Jadual 2. Dapatan jelas menunjukkan penggunaan FC mendorong pengajaran dan pembelajaran yang efektif. $70 \%$ iaitu 7 daripada 8 orang sampel menyatakan bahawa mereka mudah, senang dan ingat konsep Sake Beda semasa menjalankan operasi penambahan dan penolakan pecahan. 70 peratus sampel juga bersetuju bahawa Fc membantu mereka memahami topik pengoperasian ini. Ini jelas menunjukkan FC mampu menarik minat pelajar dan meningkatkan kefahaman mereka terhadap topik pengoperasi pecahan khususnya topik penambahan dan penolakan pecahan.

Dapatan ini selari dengan kelakuan pelajar sebelum intervensi diperkenalkan dan semasa intervensi diperkenalkan. Kod 1 hingga 8 menunjukkan tingkah laku murid sebelum intervensi dijalankan dan semasa intervensi dilaksanakan. Kod tersebut adalah seperti berikut.

1. Bercakap yang tiada kaitan dengan topik

2. Pemikiran di tempat lain (berangan)

3. Berjalan dari satu tempat ke tempat lain

4. Membuat kerja lain

5. Mengganggu murid lain secara fizikal

6. Mencuba menarik perhatian

7. Mengasah pensel

8. Keluar bilik darjah

Apabila penyelidik melakukan pemerhatian terhadap pelajar berkenaan. Penyelidik mendapati berlaku perubahan tingkah laku sebelum intervensi diperkenalkan dan semasa intervensi dijalankan. Jadual 3 menunjukkan tingkah laku yang dilakukan oleh pelajar berkenaan sebelum intervensi diperkenalkan. Dapatan menunjukkan berlaku penurunan tingkah laku negatif selepas FC diperkenalkan. Perbezaan ini digambarkan menerusi Jadual 4.

Jadual 2. Ringkasan Temu bual Bersama Sampel

\begin{tabular}{|c|c|c|}
\hline Soalan Temu Bual & Respon Murid & Peratusan Bersetuju \\
\hline $\begin{array}{l}\text { Adakah guru anda pernah } \\
\text { menggunakan Bahan Bantu } \\
\text { Mengajar semasa mengajar } \\
\text { topik pecahan? Contoh }\end{array}$ & $\begin{array}{l}\text { Ada, Antara bahan yang } \\
\text { digunakan oleh guru seperti } \\
\text { kek, roda impian, lukisan } \\
\text { kotak }\end{array}$ & $100 \%$ \\
\hline $\begin{array}{l}\text { Apakah perasaan anda } \\
\text { mempelajari pecahan } \\
\text { menggunakan FC }\end{array}$ & $\begin{array}{l}\text { Seronok, } \\
\text { Banyak perkataan yang baru } \\
\text { Gembira }\end{array}$ & $80 \%$ \\
\hline $\begin{array}{l}\text { Setelah menggunakan modul, } \\
\text { adakah topik penambahan dan } \\
\text { penolakan pecahan sukar } \\
\text { difahami }\end{array}$ & $\begin{array}{l}\text { Mudah } \\
\text { Senang } \\
\text { Ingat Sake Beda je }\end{array}$ & $70 \%$ \\
\hline $\begin{array}{l}\text { Adakah anda bersetuju FC } \\
\text { membantu anda memahami } \\
\text { operasi pecahan dan } \\
\text { penolakan pecahan }\end{array}$ & Ya & $70 \%$ \\
\hline
\end{tabular}


Jadual 3 Tingkah Laku murid sebelum FC

\begin{tabular}{|c|c|c|c|c|c|c|c|c|c|c|c|}
\hline \multirow{2}{*}{ Murid } & \multicolumn{9}{|c|}{ Pemerhatian } & \multicolumn{1}{l|}{} \\
\cline { 2 - 13 } & 1 & 2 & 3 & 4 & 5 & 6 & 7 & 8 & 9 & 10 & Peratus \\
\hline Sampel 1 & 3 & 4 & & & 3 & & & 8 & & & $40 \%$ \\
\hline Sampel 2 & 2 & & & & & & 2 & & & 2 & $30 \%$ \\
\hline Sampel 3 & 2 & & & 1 & & & 4 & 4 & & & $40 \%$ \\
\hline Sampel 4 & & 7 & & & 4 & 4 & & & & & $30 \%$ \\
\hline Sampel 5 & & 6 & & & & & & & & & $10 \%$ \\
\hline Sampl 6 & & 5 & & & & 3 & 3 & & & & $30 \%$ \\
\hline Sampel 7 & & 5 & & & & 2 & 2 & & & & $30 \%$ \\
\hline Sampel 8 & 1 & 5 & 5 & & & & 5 & & & 5 & $50 \%$ \\
\hline Sampel 9 & 1 & & & & & & & & & & $10 \%$ \\
\hline Sampel 10 & 1 & 1 & 1 & 1 & & & & & 8 & 1 & $60 \%$ \\
\hline
\end{tabular}

Dapatan menunjukkan bahawa berlaku penurunan tingkah laku negatif di dalam kelas. Murid sampel 8 dan sampel 10 menunjukkan penurunan yang ketara iaitu perbezaan sebanyak 40\%. Manakala sampel yang lain menunjukkan penurunan sekitar 10\% hingga 20\% sahaja. Ini menunjukkan terdapat perubahan tingkah laku yang positif kepada pelajar dan pelajar memberikan tumpuan kepada pengajaran dan pembelajaran yang guru sedang jalankan. Hal ini membuktikan bahawa FC mampu memberikan kesan yang positif kepada tingkah laku mereka sekali gus meningkatkan pencapaian matematik (pecahan).

Dapatan kajian ini memberi implikasi kepada pengkaji dan guru untuk lebih bersedia dan lebih beka terhadap permasalah miskonsepsi yang berlaku pada topik pecahan. Penggunaan FC sebagai bahan bantu mengajar adalah tepat keran berjaya membina pengalaman yang menyeronokkan. Hal ini mampu meningkatkan minat pelajar ke atas mata pelajaran matematik khususnya topik pecahan. Dapatan ini menyokong pernyataan Pradhana dan Latifah (2013) bahawa pembelajaran melalui permainan mampu memberi kesan yang positif ke atas pelajar. Mohd Amin Mohd Noh, et. al (2016) juga menyatakan bahawa bahan bantu pengajaran adalah penting bagi memperbaiki tahap kecemerlangan pelajar. Ini sekali gus membuktikan bahawa bahan yang di bawa oleh penyelidik merupakan bahan bantu mengajar yang baik kerana mampu menyelesaikan masalah penyelidik.

Jadual 4 Perbezaan Tingkah Laku Sampel

\begin{tabular}{ccc}
\hline Murid & Sebelum & Semasa \\
\hline Sampel 1 & $40 \%$ & $20 \%$ \\
Sampel 2 & $30 \%$ & $20 \%$ \\
Sampel 3 & $40 \%$ & $10 \%$ \\
Sampel 4 & $30 \%$ & $30 \%$ \\
Sampel 5 & $10 \%$ & $10 \%$ \\
Sampel 6 & $30 \%$ & $10 \%$ \\
Sampel 7 & $30 \%$ & $20 \%$ \\
Sampel 8 & $50 \%$ & $10 \%$ \\
Sampel 9 & $10 \%$ & $10 \%$ \\
Sampel 10 & $60 \%$ & $20 \%$ \\
\hline
\end{tabular}

\section{KESIMPULAN}

Cabaran utama dalam melaksanakan pengajaran dan pembelajaran secara bermain adalah ketidakmampuan guru kerana kurang pengalaman dan kurang melaksanakannya di sekolah. Penghasilan bahan pengajaran dan pembelajaran seperti FC ini amatlah baik dan perlu mengambil kira pelbagai aspek seperti keperluan dan keinginan kanak-kanak untuk terus belajar. Jadi, pembangunan FC pada peringkat sekolah rendah tahun 4 perlu relevan, mencabar, dan memotivasikan pelajar untuk terus belajar. Kajian ini akan membuktikan bahawa aktiviti pembelajaran melalui bermain yang diterapkan dalam FC berupaya memberikan pelajar pengalaman pembelajaran 
matematik yang bermakna. Kajian ini juga membuktikan pembinaan konsep matematik tidak dilihat sebagai sesuatu yang perlu dipindahkan secara pasif, malah perlu dibina sendiri oleh pelajar secara aktif melalui pengalaman konkrit. Secara amnya, kajian ini berjaya menyelesaikan masalah pembelajaran pelajar dari aspek pecahan khususnya dalam operasi penambahan dan penolakan.

Melalui pembelajaran berasaskan FC ini diharap enam kesilapan yang sering dilakukan oleh pelajar semasa menyelesaikan operasi penambahan dan penolakan pecahan juga dapat dikurangkan. Kesilapan tersebut adalah seperti kurang kefahaman terhadap proses yang terlibat, kesukaran dalam menukarkan kepada penyebut yang sama sebelum melakukan operasi tambah, kesilapan dalam pengiraan, dan kesukaran dalam menukar pecahan tak wajar kepada nombor bercampur. Melalui pembelajaran ini juga, diharap kosa kata pelajar tahun 4 dapat dipertingkatkan agar penggunaan bahasa Melayu mereka lebih baik. Interaksi dengan rakan semasa bermain bukan sahaja meningkatkan bahasa Melayu dan matematik, tetapi juga kemahiran berfikir kritis dan kemahiran kepimpinan pelajar. Perkara ini mungkin dapat dibuktikan melalui kajian lanjutan berbentuk eksperimen pada masa akan datang. Melalui aktiviti FC yang dirancang, pelajar membina bahasa dan pemahaman matematik secara emergent tanpa bimbingan guru sepenuhnya. FC diharap memberi implikasi yang positif ke atas misi dan aspirasi pendidikan negara kelak.

\section{RUJUKAN}

Abdul Rasid, J., \& Hasmah, I. (2013). Pelaksanaan Pembelajaran Menyeronokkan dalam Pengajaran dan Pembelajaran Bahasa Melayu. Jurnal Pendidikan Bahasa Melayu, 3(2), 49-63.

Huang, W. H., \& Soman, D. (2013). A Practitioners' Guide To Gamification Of Education. Toronto.

Kementerian Pendidikan Malaysia. (2014). Dokumen Standard Kurikulum Dan Pentaksiran Matematik Tahun 6 KSSR. KSSR.

Lortie-Forgues, H., \& Siegler, R. S. (2017). Conceptual knowledge of fraction arithmetic. Journal of Educational Psychology, 209(3), 374-386.

Mohd Afifi, B. S.(2017). Pembangunan dan Pengujian Modul Pengajaran Berasaskan Adventure terhadap Pencapaian Matematik, Kemahiran Berfikir Kritis dan Kemahiran Kepimpinan (Tesis Doktor Falsafah Tidak Diterbitkan). Tg Malim: Universiti Pendidikan Sultan Idris

Mohd Afifi, B. S., Nor'ain, M. T., \& Mazlini, A. (2016). Walking, Explore Race and Flying Fox Adventure Activity in Learning Statistics : Effect on Leadership Skills. Jurnal Didaktik Matematika, 3(2), 1-8.

Mohd Amin, M. N., Mohd Faeez, I., Kalthom H., \& , Muhammad Syakir Sulaiman, M. A. (2016). Inisiatif dan Usaha Guru dalam Meningkatkan Pengetahuan Semasa Penggunaan Bahan Bantu Mengajar. Journal of Social Sciences and Humanities, 3(3), 133-144.

Mok, S. S. (1993). Pengajaran Matematik Untuk Kursus Perguruan. Kuala Lumpur: Kumpulan Budiman Sdn Bhd.

Nah F.FH., Zeng Q., Telaprolu V.R., Ayyappa A.P., Eschenbrenner B. (2014) Gamification of Education: A Review of Literature. In: Nah F.FH. (eds) HCI in Business. HCIB 2014. Lecture Notes in Computer Science, vol 8527. Springer, Cham

Nor'ain, M. T., Marzita, P., Mazlini, A., Abdullah, M. F. N. L., \& Amalina, I. (2015). Persepsi Dan Amalan Pengajaran Guru Matematik Dalam Penyelesaian Masalah Algebra. Jurnal Pendidikan Sains \& Matematik Malaysia, 5(2), 12-22.

Noraini, I. (2005). Pedagogi Dalam Pendidikan Matematik. Kuala Lumpur: Utusan Publication \& Distributors Sdn Bhd.

Pradhana, D. T., \& Latifah, L. (2013). Pengaruh Kosa Kata Bahasa Inggris, Dasar Komputer Dan Akuntansi Terhadap Prestasi Belajar Myob. Jurnal Pendidikan Ekonomi Dinamika Pendidikan, 8(2), 75-84. https://doi.org/10.15294/dp.v8i2.3363

Yeoh, C. L., Mohd Afifi, B. S., Ket, L. L., \& Sing, N. (2015). Aplikasi Matematik. Bangi: Pelangi Professional Publishing Sdn. Bhd.

Zakiah Salleh, Norhapidah Mohd Saad, Mohamad Nizam Arshad, Hazaka Yunus, \& Effandi Zakaria. (2013). Analisis jenis kesilapan dalam operasi penambahan dan penolakan pecahan. Jurnal Pendidikan Matematik, 1(1), 1-10. 